Research Paper

\title{
Clinical Significance of BCL2, C-MYC, and BCL6 Genetic Abnormalities, Epstein-Barr Virus Infection, CD5 Protein Expression, Germinal Center B Cell/Non-Germinal Center B-Cell Subtypes, Co-expression of MYC/BCL2 Proteins and Co-expression of MYC/BCL2/BCL6 Proteins in Diffuse Large B-Cell Lymphoma: A Clinical and Pathological Correlation Study of 120 Patients
}

Choo-Yuen Ting ${ }^{\circledR}$, Kian-Meng Chang ${ }^{1}$, Jew-Win Kuan ${ }^{3}$, Jameela Sathar ${ }^{1,2}$, Lee-Ping Chew ${ }^{2,4}$, Oy-Leng Jacqueline Wong5, Yusri Yusuf ${ }^{5}$, Lily Wong6, Ahmad Toha Samsudin 7 , Mohd Nurjaya Bin Mohd Pana ${ }^{7}$, , Suk-Kam Lee ${ }^{8}$, Navarasi S. Raja Gopal ${ }^{8}$, Rita Puri ${ }^{1}$, Tee-Chuan Ong ${ }^{1}$, Samsol Kamal Bahari ${ }^{1}$, Ai-Sim Goh ${ }^{9}$, Ching- Soon Teoh ${ }^{9}$

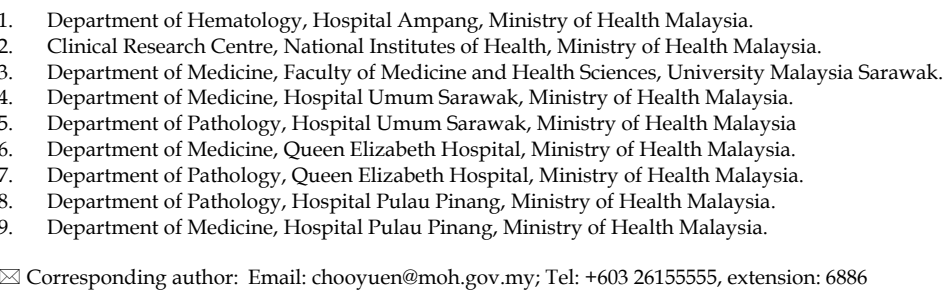

(c) Ivyspring International Publisher. This is an open access article distributed under the terms of the Creative Commons Attribution (CC BY-NC) license (https:// creativecommons.org/licenses/by-nc/4.0/). See http://ivyspring.com/terms for full terms and conditions.

Received: 2018.06.02; Accepted: 2018.07.29; Published: 2019.04.20

\begin{abstract}
Background: Clinical significance of germinal center B-cell (GCB) and non-GCB sub-categorization, expression of MYC, $B C L 2, B C L 6, C D 5$ proteins and Epstein Barr virus encoded RNA (EBER) positivity in diffuse large B-cell lymphoma (DLBCL) remain controversial. Could these biomarkers accurately identify high risk DLBCL patients? Are MYC, BCL2 and BCL6 proteins expression feasible as baseline testing to predict $c-M y c, B C L 2$ or $B C L 6$ gene rearrangements?

Aims: To investigate prognostic values of GCB/non-GCB sub-categorization, Double Protein Expression Lymphoma (DPL), Triple Protein Expression Lymphoma (TPL), positivity of CD5 protein and EBER in patients with DLBCL disease. To evaluate correlation between $B C L 2, C-M y c$ and $B C L 6$ gene rearrangements with $B C L 2, M Y C$ and $B C L 6$ proteins expression.

Methods: Diagnostic tissue samples of 120 DLBCL patients between January 2012 to December 2013 from four major hospitals in Malaysia were selected. Samples were subjected to immunohistochemical staining, fluorescent in-situ hybridization (FISH) testing, and central pathological review. Pathological data were correlated with clinical characteristics and treatment outcome.

Results: A total of 120 cases were analysed. Mean age of diagnosis was 54.1 years $\pm 14.6,64$ were males, 56 were females, mean follow up period was 25 months (ranged from 1 to 36 months). Of the 120 cases, $74.2 \%$ were non-GCB whereas $25.8 \%$ were GCB, $6.7 \%$ were EBER positive, $6.7 \%$ expressed CD5 protein, $13.3 \%$ were DPL and $40 \%$ were TPL. The prevalence of c-Myc, BCL2, BCL6 gene rearrangements were $5.8 \%, 5.8 \%$, and $14.2 \%$, respectively; and $1.6 \%$ were Double Hit Lymphoma (DHL). EBER positivity, DPL, TPL, c-Myc gene rearrangement, BCL2 gene rearrangement, extra copies of $B C L 2$ gene and $B C L 6$ gene rearrangement were associated with shorter median overall survival $(P<0.05)$. IPI score was the significant determinants of median overall survival in DPL and TPL $(P<0.05)$. CD5 protein expression and $G C B /$ non-GCB sub-categorization did not affect treatment outcome $(P>0.05)$. Overall, $C-M y c, B C L 2$ and $B C L 6$ gene rearrangements showed weak correlation with expression of MYC, BCL2 and BCL6 proteins $(P>0.05)$. Fluorescent in situ hybridization is the preferred technique for prediction of treatment outcome in DLBCL patients.

Conclusion: $c-M y c, B C L 2$, and $B C L 6$ gene rearrangements, EBER expression, DHL, TPL and IPI score are reliable risk stratification tools. MYC, BCL2 and BCL6 proteins expression are not applicable as baseline biomarkers to predict c-Myc, $B C L 2$, and $B C L 6$ gene rearrangements.
\end{abstract}

Key words: diffuse large B-cell lymphoma, $c-M y c, B C L 2$ and $B C L 6$ gene rearrangements, diffuse large B-cell lymphoma with CD5 protein expression, diffuse large B-cell lymphoma with positive EBER expression, non-germinal center B-cell subtype, Asia 


\section{Introduction}

Diffuse large B-cell lymphoma (DLBCL) appears as one of the malignancies of major public health concern, accounting for $30 \%$ to $58 \%$ and $25 \%$ to $35 \%$ of non-Hodgkin lymphomas (NHL) in EU5 (France, Germany, Italy, Spain, United Kingdom) and United States of America, respectively [1]. A study at Queen Elizabeth Hospital in Sabah, Malaysia revealed that approximately $65.1 \%$ of NHL cases were DLBCL [2]. This disease is genetically heterogenous, exhibits variations in clinical presentation and results in inconsistent treatment outcomes. The International Prognostic Index (IPI) [3] has been routinely used to stratify risk in DLBCL patients in the current clinical setting. The utilization of several genetic and proteomic testing has enabled disease prognostication and facilitated selection of optimum, individualized risk-adapted therapy. Reports of prospective clinical trials have led to application of various treatment approaches in addition to the existing standard regimen RCHOP-like therapy (rituximab, cyclophosphamide, doxorubicin, vincristine, and prednisone). Examples of such additional treatments are upfront autologous stem cell transplantation (SCT) for patients with advanced stage disease [4], alternative regimen such as DA-EPOCH-R (dose-adjusted etoposide, cyclophosphamide, doxorubicin, vincristine, prednisone, and rituximab) for patients with positive BCL6 protein expression [5], as well as novel therapeutic agents such as Ibrutinib and Bortezomib specifically to downregulate NF-kB pathway in activated B-cell subtype DLBCL [6] [7].

This study sought to identify parameters associated with inferior overall survival (OS). Both immunohistochemical testing (CD20, CD3, Ki67, Pax5, CD10, BCL6, MUM1, MYC protein, BCL2, CD5, CD23, Cyclin D1 and EBER) and fluorescent in-situ hybridization testing (FISH) (BCL2, BCL6 and $c-M y c$ gene rearrangements) were done to correlate the pathological findings with the patients' clinical features and treatment outcomes. Though various biomarkers have been evaluated, the results were controversial [8][9][10], and they were further complicated by introduction of new variants or subtypes of aggressive B cell lymphomas [11]. This study will provide us a guideline on selecting biomarkers to identify high risk DLBCL patients.

\section{Materials and methods}

\section{Ethical approval and consent to participate}

This research was performed in accordance with the Declaration of Helsinki. Analysis on archival diagnostic biopsy specimens of diffuse large B-cell lymphoma patients was approved by Medical
Research Ethics Committee, Ministry of Health Malaysia with research ID NMRR-13-973-17683. Formalin-fixed paraffin embedded tissue samples used in this study were leftover materials from the patients' diagnostic samples. All these samples were anonymized during the study and Malaysian Research Ethics Committee waived the need for written informed consent.

\section{Study Design and study subjects}

This was a retrospective cohort study on pathological, clinical features and treatment outcome of DLBCL patients. All de novo DLBCL, not otherwise specified [12] diagnosed at four major public hospitals in Malaysia [Hospital Ampang - National Hematology Referral Centre (Selangor), Queen Elizabeth Hospital (Sabah), Hospital Pulau Pinang (Penang) and Sarawak General Hospital (Kuching, Sarawak)] in year 2012 and 2013 were included in this study. A 3-year retrospective patients' clinical data (from January 2012 till December 2015) was collected. Patients with primary central nervous system lymphoma, primary mediastinal B-cell lymphoma were excluded from this study. Diagnostic formalinfixed paraffin-embedded tissue blocks for the selected cases were identified by the pathologists and were obtained from the respective laboratories. These samples were sent to Hematopathology Laboratory, Hematology Department of Hospital Ampang for hematoxylin-eosin staining, immunohistochemical staining and FISH testing. The slides produced were reviewed by five pathologists from the four hospitals in two sessions of central pathological review meeting.

Clinical data of these DLBCL patients were retrieved from the hospital information system of these four major public hospitals. Sixty-four patients received RCHOP-like chemotherapy, 34 were treated with CHOP-like chemotherapy, eight were treated with Methotrexate-based regimen, two patients received dose adjusted $\mathrm{EPOCH}$ therapy and the remaining six received palliative therapy only. Six patients were given SCT after the first line chemotherapy treatments. For the purpose of homogeneity of treatment for survival analysis, only patients who were uniformly treated with RCHOP-like or CHOPlike chemotherapy without autologous transplantation were included in the statistical analysis.

Treatment outcomes analysed included complete remission (CR) at post 6 cycles of RCHOP-like or CHOP-like chemotherapy treatment, overall survival (OS) and 2-year survival rate. CR was defined as regression of nodal mass to less than $1.5 \mathrm{~cm}$ in the longest transverse diameter of a lesion, no extralymphatic sites of disease, normalized size of organ 
affected, no disease detected in bone marrow, absence of new lesion, and free from non-measured lesions [13]. OS was measured from the date of diagnosis until 31 $1^{\text {st }}$ December 2015 or till death (with death could be attributed to either disease related or treatment related).

\section{Hematoxylin-Eosin and Immunohistochemistry staining}

$2 \mu \mathrm{m}$ thick tissue sections were prepared from paraffin tissue blocks, place on charged slides (Matsunami Platinum PRO Adhesive Glass Slide) and were stained with hematoxylin-eosin stains and immunohistochemistry staining. Reactive lymphoid hyperplasia tonsil tissue samples were used as control tissue for CD20, CD3, PAX-5, Ki67, CD5, CD23, Cyclin D1, CD10, BCL6, MUM1, BCL2 antibodies used in this study. As for MYC staining, positive control tissue samples for MYC protein were applied whereas tissue samples positive for Eptein-Barr virus were used as control tissue for Epstein-Barr virus encoded ribonucleic acid (RNA) (EBER) assay.

\section{Cut-off points for CD10, BCL6, MUM 1 and BCL2 immunohistochemical staining}

Hans' algorithm [14] was applied to classify DLBCL into germinal center B-cell subtype (GCB) and non-GCB subtype. Cut-off point for CD10 protein was $>30 \%$ of positive membranous staining on tumor cells; BCL6 protein was $>30 \%$ positivity of tumor nuclei; MUM1 protein was $>30 \%$ nuclear positivity on tumor cells. Cut-off points set for MYC was $>40 \%$ nuclear positivity on tumor nuclei whereas BCL2 protein was $>50 \%$ of tumor cells with positive cytoplasmic staining reaction, similar to that used in other study [15].

\section{Cut-off point for Epstein-Barr virus-encoded RNA (EBER) in situ hybridization testing}

In this study, a cut-off point of $50 \%$ positivity on tumor cells was applied for EBER positive DLBCL as previously described [16].

\section{Immunohistochemistry Antibodies}

Immunohistochemistry staining was performed on Ventana BenchMark GX using OptiView DAB IHC Detection Kit (Ventana Medical Systems, Tucson USA) whereas EBER immunohistochemical staining was performed on Bond-Max instrument (Leica, Newcastle Upon Tyne, UK) using Bond Polymer Refine Detection kit (Leica Biosystems, Newcastle Upon, United Kingdom). The test protocols and the antibodies used for immunohistochemistry staining are shown in Table 1.

\section{Fluorescent in situ hybridization testing (FISH)}

Fluorescent in situ hybridization analysis was performed on $3 \mu \mathrm{M}$ thick tissue sections to determine genes arrangements of this study cohort. DNA break apart probes used were Dako MYC (8q24), Dako BCL2 (18q21) and Dako BCL6 (3q27). The positive threshold set for gene rearrangement was more than $10 \%$ of the tumor cells demonstrate split signals; with distance between the separated green and red signals twice the size of the biggest signal [17]. In addition, a case was considered positive for extra gene copies if more than $10 \%$ of the tumor cells within the tissue specimen expressed three or more pairs of normal fused signals or without gene rearrangement [18].

\section{Statistical analysis}

Association between clinicopathological data of study subjects, their immunohistochemistry biomarkers expression, and genetic features were performed using either the Fisher's exact analysis or Pearson Chi Square test. Mann-Whitney test was applied to compare median age of diagnosis between EBER positive and EBER negative group.

The prognostic implications which include CR rate (within 12 months after initiation of treatment), and 2-year survival rate of $c-M y c, B C L 2$ and BCL6 gene rearrangements, EBER positivity, $\mathrm{CD} 5$ protein expression and GCB/non-GCB subtypes were evaluated using the Fisher's exact test or Pearson Chi square analysis. Correlation between MYC, BCL2 and BCL6 proteins and $c-M y c, B C L 2$ and $B C L 6$ gene rearrangements were performed by Pearson Bivariate Correlations analysis. OS was measured from the date of diagnosis until patient's death. Median OS was performed using Kaplan-Meier graph, while the comparison of median OS between groups were estimated using the log-rank test. $P$-value $<0.05$ was considered statistically significant.

\section{Results}

Initially, a total of 278 cases were selected and evaluated for this study, 91 cases were then excluded due to incomplete clinical data (67 cases), inadequate tissue biopsy material for testing (60 cases), poorly preserved tissue samples (15 cases) and poor quality FISH signals (16 cases). Eventually, only 120 cases of de novo DLBCL were included in this study.

The age range of the diagnosis of our DLBCL cohort was 18 to 86 years. The mean age of diagnosis was $54.1 \pm 14.6$, as shown in Table 2 , with male : female ratio of $1.14: 1$. From a total of 120 patients, $43.3 \%$ of the diagnostic specimens were lymph node tissue biopsy, Waldeyer's ring samples accounted for $14.2 \%$ and the remaining $42.5 \%$ of samples were from extranodal sites. The most common extranodal sites were gastrointestinal tract $(20.9 \%)$, followed by head and neck $(8.4 \%)$, respiratory system $(5.0 \%)$, skin and 
soft tissue $(3.3 \%)$, skeletal tissue $(2.5 \%)$, genitourinary $(0.8 \%)$, breast tissue $(0.8 \%)$ and pancreas $(0.8 \%)$.

Using Hans algorithm, $74.2 \%$ of 120 patients were classified as non-GCB subtype and only $25.8 \%$ as GCB subtype. Both GCB and non-GCB showed comparable $\mathrm{CR}$ rates [(RCHOP-like treated-GCB subtype versus RCHOP-like treated non-GCB subtype: $50.0 \%$ versus $69.5 \%, P=0.142$ ); (CHOP-like treated-GCB subtype versus $\mathrm{CHOP}$ treated non-GCB subtype: $28.5 \%$ versus $25.9 \%, P=0.872)]$ and comparable median OS [(RCHOP-like treated-GCB subtype versus RCHOPlike treated non-GCB subtype: 27.6 months \pm 2.9 versus 29.0 months $\pm 1.7, P=0.361$, $C H O P$ treated-GCB subtype versus CHOP treated non-GCB subtype: 19.7 months \pm 4.4 versus 21.6 months $\pm 2.3, P=0.895)]$.

No significant correlation was found between DLBCL subtypes with age of diagnosis, gender, IPI scores, disease stage, serum lactate dehydrogenase level $(\mathrm{LDH})$ and 2-year survival rate $(P>0.05)$. However, incidence of nodal DLBCL (excluding Waldayer's ring) was higher among GCB subtype, while extranodal DLBCL was more frequent in non-GCB subtype $(P=0.061)$.

Epstein Barr virus encoded RNA (EBER) was detected in 8 patients $(6.7 \%)$. No significant difference in distribution of GCB and non-GCB subtype was found between EBER positive group and EBER negative group $(P=0.424)$. Mean age of diagnosis for EBER positive group was not significantly different from EBER negative group (58.0 \pm 10.7 versus $53.8 \pm$ $14.9, P=0.573)$. Majority of the EBER positive cases had low IPI scores ( 1 to 2$),(87.5 \%, P=0.137)$. Of the 8 EBER positive cases, one patient was treated with SCT, one patients with palliative therapy; statistical analysis were performed on five patients who were treated with RCHOP-like chemotherapy and one patient on CHOP-like therapy. RCHOP-like treatedEBER positive group had significantly shorter OS period than the RHOP-like treated-EBER negative group (17.8 months \pm 4.3 versus 29.5 months $\pm 1.5, P$ $=0.008)$ and lower 2-year survival rate $(20 \%$ versus $76 \%, P=0.008)$. Within EBER positive group, disease stage was the key factor affecting OS. EBER positive patients with stage 111 to $\mathrm{lV}$ disease had significant shorter OS duration compared to the EBER positive patients with stage 1 to 11 disease [7.5 months \pm 2.5 versus 24.6 months $\pm 3.5, P=0.039]$. Patient's age, gender, site of disease and GCB/non-GCB subtypes showed no correlation with overall survival.

CD5 protein expression was positive in 8 patients $(6.7 \%)$ with equal distribution between male and female DLBCL patients (4:4). No significant difference was found between mean age of diagnosis for patients with positive CD5 protein expression (58.3 years \pm 7.8 ) and those with negative CD5 protein expression (53.8 years \pm 15.0 ) with $P=0.542$. Positive CD5 protein expression is associated with aggressive disease and poor prognosis. Majority of the patients with positive CD5 protein expression had high IPI score (more than 2$)(75 \%$ versus $39.3 \%, P=0.066)$ and advance stage disease (stage III to IV, $87.5 \%$ versus $54.5 \%, P=0.069$ ). From a total of 8 patients with CD5 protein expression, $4 / 8$ were treated with $\mathrm{CHOP}$ chemotherapy, $1 / 8$ with RCHOP-like chemotherapy, $2 / 8$ with palliative therapy and $1 / 8$ were treated with methotrexate-based chemotherapy. In RCHOP-like treatment group, no significant difference was observed in median OS between CD5 protein positive group and CD5 protein negative group ( 9 months \pm 0 versus 24.1 months $\pm 1.3, P=0.732$ ). For $C H O P$-treated group, the median OS of CD5 protein positive group was also statistically insignificant from CD5 protein negative group (12.5 months \pm 5.5 versus 22.3 months $\pm 2.1, P=0.257$ ). CD5 protein positive-high IPI scores patients who were treated with $\mathrm{CHOP}$-like had the worst treatment outcome, their survival period ranged from 2 months to 14 months (median survival period of 6.6 months). 2-year OS rate for CHOP-like treated-CD5 protein positive group was lower than the $\mathrm{CHOP}$-like treated-CD5 protein negative group ( $25 \%$ versus $46 \%, P=0.257$ ).

The prevalence of Double Protein Expression Lymphoma (DPL) (co-expression of MYC and BCL2 protein), and Triple Protein Expression Lymphoma (TPL) (co-expression of MYC, BCL2 and BCL6 proteins) in our cohort were $13.3 \%$ (16 patients) and $40 \%$ (48 patients), respectively. Their clinicopathological characteristics and treatment outcomes are shown in Table 3.

The prognostic values of patients with positive MYC/BCL2 proteins co-expression (DPL) were evaluated. DPL was more prevalent among older patients (60.3 years \pm 15.8 versus 52.1 years \pm 14.7 ; $P=0.048)$. All of them were non-GCB subtype $(P=0.008)$ and this group had higher rate of MYC gene rearrangement $(18.7 \%)(P=0.02)$. Shorter median OS was observed among RCHOP-like treated-DPL compared to RCHOP-like treated-non-DPL (17.7 months \pm 4.4 versus 29.8 months $\pm 1.9, P=0.080$ ).

As for those on CHOP-like treatment, shorter median OS was also observed in DPL group compared to the non-DPL group (19.6 months \pm 4.6 versus 27.6 months $\pm 2.6, P=0.089$ ).

Within the DPL group, IPI score was still a significant factor in determining overall survival period. Median OS of RCHOP-like treated-DPL patients with high IPI score of 3 to 5 was significantly shorter than those with low IPI score of 1 to 2 (13.5 months \pm 10.7 versus 32.5 months $\pm 9.9, P=0.018$ ). Such observation was not found in CHOP-like treated 
group. Median OS of CHOP-like treated-DPL patients with high IPI score of 3 to 5 was not statistically different from those with low IPI score of 1 to 2 (17.5 months \pm 10.0 versus 25.0 months $\pm 9.2 ; P=0.895$ ).

Approximate $40 \%$ of the patients were TPL. Median OS of RCHOP-like treated-TPL group was shorter compared to the RCHOP-like treated-non-TPL group (22.6 months \pm 1.9 versus 29.8 months \pm 1.9 ; $P=0.053$ ). Similar finding was found in patients treated with CHOP-like therapy. Median OS of CHOP-like treated-TPL group was significantly shorter compared to CHOP-like treated-non-TPL group (14.1 months \pm 3.1 versus 27.6 months \pm 2.6 , $P=0.002)$.

Table 1. Antibodies and protocols used for immunohistochemistry staining

\begin{tabular}{|c|c|c|c|c|c|c|}
\hline & Antibody & Clone & $\begin{array}{l}\text { Monoclonal/ } \\
\text { polyclonal }\end{array}$ & Manufacturer & $\begin{array}{l}\text { Epitope Retrieval } \\
\text { Condition }\end{array}$ & $\begin{array}{l}\text { Antibody Incubation } \\
\text { Period }\end{array}$ \\
\hline 1 & CONFIRM Anti-CD20 & L26 & Mouse Monoclonal & Ventana Medical System, & CC1 $16 \mathrm{~min}$ & $10 \mathrm{~min}$ \\
\hline 2 & Anti-BCL-2 & SP66 & Rabbit monoclonal & Tucson, United States & CC1 $64 \mathrm{~min}$ & $16 \mathrm{~min}$ \\
\hline 3 & Anti-CD5 & SP19 & & & CC1 $32 \mathrm{~min}$ & $16 \mathrm{~min}$ \\
\hline 4 & Anti-CD23 & SP23 & & & CC1 $48 \mathrm{~min}$ & $16 \mathrm{~min}$ \\
\hline 5 & Anti-Ki-67 & $30-9$ & & & CC1 $64 \mathrm{~min}$ & $16 \mathrm{~min}$ \\
\hline 6 & MUM1 & MRQ-43 & & & CC1 $32 \mathrm{~min}$ & $16 \mathrm{~min}$ \\
\hline 7 & Anti-PAX5 & SP34 & & & CC1 $32 \mathrm{~min}$ & $16 \mathrm{~min}$ \\
\hline 8 & Anti-MYC & Y69 & & & CC1 $64 \mathrm{~min}$ & $32 \mathrm{~min}$ \\
\hline 9 & Anti-human BCL6 Protein & PG-B6p & Mouse Monoclonal & Dako, Glostrup, Denmark & CC1 $32 \mathrm{~min}$ & $52 \mathrm{~min}$ \\
\hline 10 & Anti-human CD10 & $56 \mathrm{C6}$ & & & CC1 $24 \mathrm{~min}$ & $32 \mathrm{~min}$ \\
\hline 11 & Anti-human CD3 & & Polyclonal rabbit & & CC1 $32 \mathrm{~min}$ & $16 \mathrm{~min}$ \\
\hline 12 & Anti-human Cyclin D1 & EP12 & Monoclonal rabbit & & CC1 $32 \mathrm{~min}$ & $32 \mathrm{~min}$ \\
\hline 13 & ISH EBER probe & & & $\begin{array}{l}\text { Leica Biosystems, Newcastle } \\
\text { Upon, United Kingdom) }\end{array}$ & & \\
\hline
\end{tabular}

Table 2. Clinicopathological characteristics and treatment outcomes of diffuse large B-cell lymphoma subtypes based on cell of origin, EBER Positive diffuse large B-cell lymphoma and CD5 protein expression.

\begin{tabular}{|c|c|c|c|c|c|c|c|c|c|c|}
\hline \multirow{2}{*}{$\begin{array}{l}\text { Clinical and } \\
\text { pathological } \\
\text { characteristics }\end{array}$} & \multirow[t]{2}{*}{ Overall } & \multicolumn{3}{|c|}{ Diffuse large B-cell lymphoma subtypes } & \multicolumn{3}{|l|}{ EBER } & \multicolumn{3}{|c|}{ CD5 Protein Expression } \\
\hline & & GCB & Non-GCB & Pvalue & Positive & Negative & Pvalue & Positive & Negative & P value \\
\hline Mean age, years (SD) & $54.1(14.6)$ & $52.4(13.5)$ & $54.7 \pm 15.1$ & 0.286 & $58.0(10.7)$ & $53.8(14.9)$ & 0.573 & $58.3(7.8)$ & $53.8(15.0)$ & 0.542 \\
\hline Age $>60$ years & $45 / 120(37.5 \%)$ & $11 / 31(35.5 \%)$ & $34 / 89(38.2 \%)$ & 0.788 & $4 / 8(50.0 \%)$ & $41 / 112(36.6 \%)$ & 0.471 & $3 / 8(37.5 \%)$ & $42 / 112(37.5 \%)$ & 0.655 \\
\hline Gender - Male & $64 / 120(53.3 \%)$ & $13 / 31(41.9 \%)$ & $51 / 89(57.3 \%)$ & 0.140 & $5 / 8(62.5 \%)$ & $59 / 112(52.6 \%)$ & 0.722 & $4 / 8(50.0 \%)$ & $60 / 112(53.6 \%)$ & 0.564 \\
\hline \multicolumn{11}{|c|}{ Diagnostic Specimen sites } \\
\hline Lymph nodes & $52 / 120(43.3 \%)$ & $20 / 31(64.5 \%)$ & $32 / 89(36.0 \%)$ & 0.061 & $4 / 8(50.0 \%)$ & $48 / 112(42.8 \%)$ & 0.942 & $4 / 8(50.0 \%)$ & $48 / 112(42.9 \%)$ & 0.103 \\
\hline Waldeyer's ring & $17 / 120(14.2 \%)$ & $1 / 31(3.2 \%)$ & $16 / 89(18.0 \%)$ & & $1 / 8(12.5 \%)$ & $16 / 112(14.3 \%)$ & & $1 / 8(12.5 \%)$ & $16 / 112(14.2 \%)$ & \\
\hline Extranodal sites & $51 / 120(42.5 \%)$ & $10 / 31(32.3 \%)$ & $41 / 89(46.0 \%)$ & & $3 / 8(37.5 \%)$ & $48 / 112(42.9 \%)$ & & $3 / 8(37.5 \%)$ & $48 / 112(42.9 \%)$ & \\
\hline \multicolumn{11}{|l|}{ Subtype } \\
\hline GCB & $31 / 120(25.8 \%)$ & NA & NA & $\mathrm{NA}$ & $3 / 8(37.5 \%)$ & $28 / 112(25.0 \%)$ & 0.424 & $0 / 8(0 \%)$ & $31 / 112(27.7 \%)$ & 0.111 \\
\hline Non-GCB & $89 / 120(74.2 \%)$ & NA & NA & NA & $5 / 8(62.5 \%)$ & $84 / 112(75.0 \%)$ & & $8 / 8(100.0 \%)$ & $81 / 112(72.3 \%)$ & \\
\hline CD5 positive & $8 / 120(6.7 \%)$ & $0 / 31(0 \%)$ & $8 / 89(9.0 \%)$ & 0.111 & $0 / 8(0 \%)$ & $8 / 112(7.1 \%)$ & 0.566 & NA & NA & NA \\
\hline EBER positive & $8 / 120(6.7 \%)$ & $3 / 31(9.7 \%)$ & $5 / 89(5.6 \%)$ & 0.424 & NA & NA & NA & $0 / 8(0 \%)$ & $8 / 112(7.1 \%)$ & 0.566 \\
\hline \multicolumn{11}{|c|}{$c-M y c$ gene rearrangement } \\
\hline Positive & $7 / 120(5.8 \%)$ & $3 / 31(9.6 \%)$ & $4 / 89(3.3 \%)$ & 0.536 & $0 / 8(0 \%)$ & $7 / 112(6.2 \%)$ & 0.736 & $0 / 8(0 \%)$ & $6 / 112(5.4 \%)$ & 0.767 \\
\hline Extra copies & $1 / 120(0.8 \%)$ & $0 / 31(0 \%)$ & $1 / 89(1.1 \%)$ & & $0 / 8(0 \%)$ & $1 / 112(/ 0.9 \%)$ & & $0 / 8(0 \%)$ & $1 / 112(0.9 \%)$ & \\
\hline \multicolumn{11}{|c|}{$B C L 2$ gene rearrangement } \\
\hline Positive & $7 / 120(5.8 \%)$ & $3 / 31(9.7 \%)$ & $4 / 89(4.4 \%)$ & 0.198 & $1 / 8(12.5 \%)$ & $6 / 112(5.3 \%)$ & 0.612 & $0 / 8(0 \%)$ & $8 / 112(7.1 \%)$ & 0.101 \\
\hline Extra copies BCL2 gene & $6 / 120(5.0 \%)$ & $0 / 31(0 \%)$ & $6 / 89(6.7 \%)$ & & $0 / 8(0 \%)$ & $6 / 112(5.3 \%)$ & & $2 / 8(25 \%)$ & $5 / 112(4.5 \%)$ & \\
\hline \multicolumn{11}{|c|}{$B C L 6$ gene rearrangement } \\
\hline Positive & $17 / 120(14.2 \%)$ & $5 / 31(16.1 \%)$ & $12 / 89(13.4 \%)$ & 0.767 & $1 / 8(12.5 \%)$ & $16 / 112(14.2 \%)$ & 0.684 & $1 / 8(12.5 \%)$ & $15 / 112(13.4 \%)$ & 0.711 \\
\hline IPI score $>2$ & $50 / 120(41.7 \%)$ & $11 / 31(35.5 \%)$ & $39 / 89(43.8 \%)$ & 0.417 & $1 / 8(12.5 \%)$ & $49 / 112(43.8 \%)$ & 0.137 & $6 / 8(75.0 \%)$ & $44 / 112(39.3 \%)$ & 0.066 \\
\hline LDH- Raised & $89 / 120(74.2 \%)$ & $26 / 31(83.9 \%)$ & $63 / 89(70.8 \%)$ & 0.176 & $7 / 8(87.5 \%)$ & $82 / 112(73.2 \%)$ & 0.678 & $7 / 8(87.5 \%)$ & $82 / 112(73.2 \%)$ & 0.678 \\
\hline Stage- III, IV & $68 / 120(56.7 \%)$ & $16 / 31(51.6 \%)$ & $52 / 89(58.4 \%)$ & 0.510 & $4 / 8(50.0 \%)$ & $64 / 112(57.1 \%)$ & 0.726 & $7 / 8(87.5 \%)$ & $61 / 112(54.5 \%)$ & 0.069 \\
\hline \multicolumn{11}{|c|}{ Treatment outcome - CR rate } \\
\hline RCHOP-like & $41 / 64(64.1 \%)$ & $9 / 18(50.0 \%)$ & $32 / 46(69.5 \%)$ & 0.142 & $2 / 5(40.0 \%)$ & $39 / 59(66.1 \%)$ & 0.341 & $0 / 1(0 \%)$ & $41 / 63(65.1 \%)$ & 0.359 \\
\hline CHOP-like & $9 / 34(26.5 \%)$ & $2 / 7(28.5 \%)$ & $7 / 27(25.9 \%)$ & 0.872 & $0 / 1(0 \%)$ & $9 / 33(27.2 \%)$ & 0.029 & $1 / 4(25.0 \%)$ & $8 / 30(26.7 \%)$ & 0.928 \\
\hline \multicolumn{11}{|c|}{ Treatment Outcome - 2-year survival rate } \\
\hline RCHOP-like & $47 / 64(73 \%)$ & $12 / 18(66 \%)$ & $35 / 46(76 \%)$ & 0.361 & $1 / 5(20 \%)$ & $45 / 59(76 \%)$ & 0.008 & $0 / 1(0 \%)$ & $46 / 63(73 \%)$ & 0.732 \\
\hline CHOP-like & $15 / 34(44 \%)$ & $2 / 7(28 \%)$ & $12 / 27(45 \%)$ & 0.895 & $0 / 1(0 \%)$ & $15 / 33(45 \%)$ & $<0.01$ & $1 / 4(25 \%)$ & $14 / 30(46 \%)$ & 0.257 \\
\hline \multicolumn{11}{|c|}{ Treatment Outcome - median OS (IQR) (month) } \\
\hline RCHOP-like & $28.6(20)$ & $27.6(21)$ & $29.0(19.0)$ & 0.361 & $17.8(22)$ & $29.5(19)$ & 0.008 & 9.0 (NA) & $24.1(20.0)$ & 0.732 \\
\hline CHOP-like & $21.3(16)$ & $19.7(24)$ & $21.6(15)$ & 0.895 & 3.0 (NA) & $21.8(15)$ & $<0.01$ & $12.5(24)$ & $22.3(15)$ & 0.257 \\
\hline
\end{tabular}

CR: complete response; EBER: Epstein-Barr virus encoded ribonucleic acid; GCB: germinal center B-cell; IQR: interquartile range; LDH: lactate dehydrogenase; NA: not available; OS: overall survival; SD: standard deviation 
Table 3. Clinicopathological characteristics and treatment outcomes of Double Protein Expression Lymphoma (DPL) and Triple Protein Expression Lymphoma (TPL).

\begin{tabular}{|c|c|c|c|c|c|c|}
\hline \multirow{2}{*}{$\begin{array}{l}\text { Clinical and pathological } \\
\text { characteristics }\end{array}$} & \multicolumn{3}{|c|}{ DPL (MYC+/BCL2+) } & \multicolumn{3}{|c|}{ TPL (MYC+/BCL2+/BCL6+) } \\
\hline & Positive & Negative & P value & Positive & Negative & P value \\
\hline Mean age, years (SD) & $60.3(15.8)$ & $52.1(14.7)$ & 0.048 & $54.1(14.9)$ & $53.9(13.4)$ & 0.810 \\
\hline Age $>60$ years & $9 / 16(56.2 \%)$ & $17 / 56(30.3 \%)$ & 0.057 & $19 / 48(39.5 \%)$ & $17 / 56(30.3 \%)$ & 0.324 \\
\hline Gender - Male & $7 / 16(43.7 \%)$ & $27 / 56(48.2 \%)$ & 0.752 & $30 / 48(62.5 \%)$ & $27 / 56(48.2 \%)$ & 0.144 \\
\hline \multicolumn{7}{|l|}{ Diagnostic specimen sites } \\
\hline Lymph nodes & $8 / 16(50.0 \%)$ & $23 / 56(41.1 \%)$ & 0.288 & $21 / 48(43.8 \%)$ & $23 / 56(41.1 \%)$ & 0.165 \\
\hline Waldeyer's ring & $1 / 16(6.3 \%)$ & $6 / 56(10.7 \%)$ & & $10 / 48(20.8 \%)$ & $6 / 56(10.7 \%)$ & \\
\hline Extranodal sites & $7 / 16(43.7 \%)$ & $27 / 56(48.2 \%)$ & & $17 / 48(35.4 \%)$ & $27 / 56(48.2 \%)$ & \\
\hline \multicolumn{7}{|l|}{ Subtype } \\
\hline GCB & $0 / 16(0 \%)$ & $19 / 56(33.9 \%)$ & 0.008 & $12 / 48(25.0 \%)$ & $19 / 56(33.9 \%)$ & 0.392 \\
\hline Non-GCB & $16 / 16(100 \%)$ & $37 / 56(66.1 \%)$ & & $36 / 48(75.0 \%)$ & $37 / 56(66.1 \%)$ & \\
\hline CD5 positive & $2 / 16(12.5 \%)$ & $1 / 56(1.7 \%)$ & 0.122 & $5 / 48(10.4 \%)$ & $1 / 56(1.8 \%)$ & 0.093 \\
\hline EBER positive & $1 / 16(6.25 \%)$ & $3 / 56(5.3 \%)$ & 0.643 & $4 / 48(8.3 \%)$ & $3 / 56(5.4 \%)$ & 0.701 \\
\hline \multicolumn{7}{|l|}{$c-M y c$ gene rearrangement } \\
\hline Positive & $3 / 16(18.7 \%)$ & $2 / 56(3.5 \%)$ & 0.020 & $2 / 48(4.2 \%)$ & $2 / 56(3.6 \%)$ & 0.631 \\
\hline Extra copies & $1 / 16(6.2 \%)$ & $0 / 56(0 \%)$ & & $0 / 48(0 \%)$ & $0 / 56(0 \%)$ & \\
\hline \multicolumn{7}{|l|}{$B C L 2$ gene rearrangement } \\
\hline Positive & $1 / 16(6.2 \%)$ & $4 / 56(7.1 \%)$ & 0.736 & $2 / 48(4.2 \%)$ & $4 / 56(7.1 \%)$ & 0.530 \\
\hline Extra copies & $0 / 16(0 \%)$ & $2 / 56(3.5 \%)$ & & $4 / 48(8.3 \%)$ & $2 / 56(3.6 \%)$ & \\
\hline \multicolumn{7}{|l|}{$B C L 6$ gene rearrangement } \\
\hline Positive & $2 / 16(12.5 \%)$ & $8 / 56(14.2 \%)$ & 0.610 & $7 / 48(14.5 \%)$ & $8 / 56(14.3 \%)$ & 0.591 \\
\hline IPI $>2$ & $9 / 16(56.2 \%)$ & $19 / 56(33.9 \%)$ & 0.106 & $22 / 48(45.8 \%)$ & $19 / 56(33.9 \%)$ & 0.234 \\
\hline LDH - Raised & $11 / 16(68.7 \%)$ & $41 / 56(73.2 \%)$ & 0.635 & $37 / 48(77.1 \%)$ & $41 / 56(73.2 \%)$ & 0.821 \\
\hline Stage - III, IV & $10 / 16(62.5 \%)$ & $29 / 56(51.7 \%)$ & 0.448 & $29 / 48(60.4 \%)$ & $29 / 56(51.8 \%)$ & 0.431 \\
\hline \multicolumn{7}{|c|}{ Treatment outcome - CR rate } \\
\hline RCHOP-like & $2 / 6(33.3 \%)$ & $19 / 30(63.3 \%)$ & 0.210 & $20 / 28(71.4 \%)$ & $19 / 30(63.3 \%)$ & 0.512 \\
\hline CHOP-like & $3 / 6(50.0 \%)$ & $5 / 16(31.2 \%)$ & 0.732 & $1 / 12(8.3 \%)$ & $5 / 16(31.2 \%)$ & 0.254 \\
\hline \multicolumn{7}{|c|}{ Treatment outcome - 2-year survival rate } \\
\hline RCHOP-like & $3 / 6(50 \%)$ & $22 / 30(73 \%)$ & 0.080 & $22 / 28(78 \%)$ & $22 / 30(73 \%)$ & 0.053 \\
\hline CHOP-like & $3 / 6(50 \%)$ & $10 / 16(62 \%)$ & 0.089 & $2 / 12(16 \%)$ & $11 / 16(68 \%)$ & 0.002 \\
\hline \multicolumn{7}{|c|}{ Treatment Outcome - median OS (IQR) (month) } \\
\hline RCHOP-like & $17.7(20)$ & $29.8(15)$ & 0.080 & $22.6(17)$ & $29.8(15)$ & 0.053 \\
\hline CHOP-like & $19.6(19)$ & $27.6(13)$ & 0.089 & $14.1(16)$ & $27.6(13)$ & 0.002 \\
\hline
\end{tabular}

CR: complete response; EBER: Epstein-Barr virus encoded ribonucleic acid; GCB: germinal center B-cell; IQR: interquartile range; LDH: lactate dehydrogenase; OS: overall survival; SD: standard deviation

IPI score was an important determinant for OS in RCHOP-like treated-TPL group. Patients with high IPI score of 3 to 5 had significant shorter median OS period than the patients with low IPI score of 1 to 2 (23.0 months \pm 4.3 versus 33.2 months $\pm 1.9 ; P=0.030$ ). However, in CHOP-like treated group, median OS of CHOP-like treated-TPL patients with high IPI score was not significantly different from CHOP-like treated-TPL patients with low IPI score (12.6 months \pm 3.4 versus 16.6 months $\pm 4.7 ; P=0.602$ ).

2-year survival rate for RCHOP-like treated-DPL was lower compared to RCHOP-like treated-TPL group (50\% versus 78\%). 2-year survival rate for CHOP-like treated group was worse compared to the RCHOP-like treated group. 2-year survival rates for CHOP-like treated-DPL group and CHOP-like treated-TPL group were $50 \%$ and $16 \%$, respectively.

The prevalence of $c-M y c, B C L 2$, and BCL6 gene rearrangements were $7(5.8 \%), 7(5.8 \%)$, and 17 $(14.1 \%)$, respectively. There were two cases of DHL (concurrent $c-M y c$ and BCL2 gene rearrangements), but no Triple Hit Lymphoma (THL) (concurrent $c-M y c, B C L 2$ and BCL6 gene rearrangements) in our study cohort. The clinicopathological characteristics and treatment outcomes of DLBCL patients with these three gene rearrangements are as shown in Table 4.

$c-M y c$ gene rearrangements were detected in 7 of 120 cases $(5.8 \%)$. $4.2 \%$ had sole $c-M y c$ gene rearrangement and $1.6 \%$ demonstrated concurrent $c-M y c$ and $B C L 2$ gene rearrangements (DHL). In addition, there was one case of $M Y C$ gene extra copies.

$c-M y c$ gene rearrangement is an indicator of poor prognosis on both low or high IPI scores and at all disease stages $(57.1 \%$ with low disease stage of 1 to 2 ; $57.1 \%$ with IPI score of 1 to 2). All c-Myc gene rearrangement positive cases (7 of 7$)$ in both RCHOP-like treatment and CHOP-like treatment experienced disease relapse or refractory disease (RCHOP-like treated group $100 \%, P=0.014$ and CHOP-like treated group: $100 \%, P=0 .=615) . c-M y c$ gene rearrangement positive group demonstrated rather low rate of 2-year survival rate, $0 \%$ in CHOP-like treated group and 33\% in RCHOP-like treated group. In contrast, $\mathrm{CHOP}-$ like treated $c-M y c$ gene rearrangement negative group and RCHOP-like treated $c-M y c$ gene rearrangement negative group had 
much higher rates of 2-year survival, $50 \%$ and $77 \%$ respectively. Compared to RCHOP-like treated $c-M y c$ gene rearrangement negative group, $\mathrm{RCHOP}-$ like treated $c-M y c$ gene rearrangement positive group had significant shorter median overall survival period (13.6 months \pm 4.6 versus 29.6 months $\pm 1.4, P<0.01$ ).
CHOP-like treated-c-Myc gene rearrangement positive group also demonstrated significant shorter median overall survival period than the CHOP-like treated $c-M y c$ gene rearrangement negative group (6.5 months \pm 2.5 versus $22.2 \pm 2.0, P<0.01$ )

Table 4. Clinicopathological characteristics of $c-M y c, B C L 2$ and BCL6 gene rearrangements; association with treatment outcomes and correlation with MYC, BCL2 and BCL6 protein expression

\begin{tabular}{|c|c|c|c|c|c|c|c|c|c|c|c|}
\hline \multirow{2}{*}{$\begin{array}{l}\text { Clinical and } \\
\text { Pathological } \\
\text { Characteristics }\end{array}$} & \multicolumn{4}{|c|}{$c-M y c$ gene rearrangement } & \multicolumn{4}{|c|}{$B C L 2$ gene rearrangement } & \multicolumn{3}{|c|}{$B C L 6$ gene rearrangement } \\
\hline & Positive & Negative & Extra copies & P Value & Positive & Negative & $\begin{array}{l}\text { Extra } \\
\text { copies }\end{array}$ & P Value & Positive & Negative & $\begin{array}{l}\mathbf{P} \\
\text { Value }\end{array}$ \\
\hline Mean age, year (SD) & $58.5(20.4)$ & $53.6(14.2)$ & 72 (NA) & 0.053 & $61(10.5)$ & $53.7(14.7)$ & $53.1(16.4)$ & 0.718 & $54.8(10.4)$ & $53.9(15.2)$ & 0.718 \\
\hline Age $>60$ years & $3 / 7(42.8 \%)$ & $\begin{array}{l}41 / 112 \\
(36.6 \%)\end{array}$ & $1 / 1(100 \%)$ & 0.531 & $4 / 7(57.1 \%)$ & $\begin{array}{l}39 / 107 \\
(36.4 \%)\end{array}$ & $2 / 6(33.3 \%)$ & 0.536 & $\begin{array}{l}6 / 17 \\
(35.2 \%)\end{array}$ & $\begin{array}{l}39 / 103 \\
(37.8 \%)\end{array}$ & 0.839 \\
\hline Gender - Male & $3 / 7(42.8 \%)$ & $\begin{array}{l}60 / 112 \\
(53.5 \%)\end{array}$ & $1 / 1(100 \%)$ & 0.843 & $3 / 7(42.8 \%)$ & $\begin{array}{l}56 / 107 \\
(52.3 \%)\end{array}$ & $5 / 6(83.3 \%)$ & 0.298 & $\begin{array}{l}5 / 17 \\
(29.5 \%)\end{array}$ & $\begin{array}{l}59 / 103 \\
(57.2 \%)\end{array}$ & 0.033 \\
\hline \multicolumn{12}{|c|}{ Diagnostic specimen sites } \\
\hline Lymph node & $3(42.9 \%)$ & $48(42.9 \%)$ & $1(100 \%)$ & & $6(85.7 \%)$ & $44(41.1 \%)$ & $2(33.3 \%)$ & & $7(41.2 \%)$ & $45(43.7 \%)$ & \\
\hline Waldeyer's ring & $3(42.9 \%)$ & $14(12.5 \%)$ & $0(\%)$ & 0.503 & $0(0 \%)$ & $15(14.0 \%)$ & $2(33.3 \%)$ & 0.569 & $1(5.9 \%)$ & $16(15.5 \%)$ & 0.029 \\
\hline Extranodal sites & $1(14.2 \%)$ & $50(44.6 \%)$ & $0(0 \%)$ & & $1(14.3 \%)$ & $48(44.9 \%)$ & $2(33.3 \%)$ & & $9(52.9 \%)$ & $42(40.8 \%)$ & \\
\hline \multicolumn{12}{|l|}{ Subtype } \\
\hline GCB & $3 / 7(42.9 \%)$ & $28 / 112(25.0 \%)$ & 0 & 0.536 & $3 / 7(42.9 \%)$ & $\begin{array}{l}28 / 107 \\
(26.2 \%)\end{array}$ & $0 / 6(0 \%)$ & 0.198 & $\begin{array}{l}5 / 17 \\
(29.4 \%)\end{array}$ & $\begin{array}{l}26 / 103 \\
(25.2 \%)\end{array}$ & 0.767 \\
\hline Non-GCB & $4 / 7(57.1 \%)$ & $84 / 112(75.0 \%)$ & 1 & & $4 / 7(57.1 \%)$ & $\begin{array}{l}79 / 107 \\
(73.8 \%)\end{array}$ & $6 / 6(100 \%)$ & & $\begin{array}{l}12 / 17 \\
(70.6 \%)\end{array}$ & $\begin{array}{l}77 / 103 \\
(74.8 \%)\end{array}$ & \\
\hline CD5 positive & $0 / 7(0 \%)$ & $8 / 112(7.1 \%)$ & $0 / 1(0 \%)$ & 0.736 & $0 / 7(0 \%)$ & $6 / 107(5.6 \%)$ & $2 / 6(33.3 \%)$ & 0.073 & $1 / 17(5.8 \%)$ & $7 / 103(6.7 \%)$ & 0.684 \\
\hline EBER positive & $0 / 7(0 \%)$ & $8 / 112(7.1 \%)$ & $0 / 1(0 \%)$ & 0.736 & $1 / 7(14.3 \%)$ & $7 / 107(6.5 \%)$ & $0 / 6(0 \%)$ & 0.612 & $1 / 17(5.8 \%)$ & $7 / 103(6.7 \%)$ & 0.684 \\
\hline \multicolumn{12}{|c|}{ c-Myc gene rearrangement } \\
\hline Positive & NA & NA & NA & NA & $2 / 7(28.5 \%)$ & $5 / 1074.7 \%)$ & $0 / 6(0 \%)$ & 0.191 & $0 / 17(0 \%)$ & $7 / 103(6.7 \%)$ & 0.331 \\
\hline Extra copies & NA & NA & NA & NA & $0 / 7(0 \%)$ & $1 / 107(0.9 \%)$ & $0 / 6(0 \%)$ & & $0 / 17(0 \%)$ & $1 / 103(0.9 \%)$ & \\
\hline \multicolumn{12}{|c|}{$B C L 2$ gene rearrangement } \\
\hline Positive & $2 / 7(28.5 \%)$ & $5 / 112(4.4 \%)$ & $0 / 1(0 \%)$ & 0.191 & NA & NA & NA & NA & $2 / 17(11.7 \%)$ & $5 / 103(4.8 \%)$ & 0.229 \\
\hline Extra copies & $0 / 7(0 \%)$ & $6 / 112(5.3 \%)$ & $0 / 1(0 \%)$ & & NA & NA & NA & NA & $1 / 17(5.8 \%)$ & $5 / 103(4.8 \%)$ & \\
\hline \multicolumn{12}{|c|}{$B C L 6$ gene rearrangement } \\
\hline Positive & $\begin{array}{l}0 / 7 \\
(0 \%)\end{array}$ & $\begin{array}{l}17 / 112 \\
(15.1 \%)\end{array}$ & $0 / 1(0 \%)$ & 0.649 & $2 / 7(28.5 \%)$ & $\begin{array}{l}14 / 107 \\
(13.0 \%)\end{array}$ & $1 / 6(16.6 \%)$ & 0.331 & NA & NA & NA \\
\hline IPI $>2$ & $3 / 7(42.9 \%)$ & $\begin{array}{l}47 / 112 \\
(41.9 \%)\end{array}$ & $0 / 1(0 \%)$ & 0.697 & $3 / 7(42.8 \%)$ & $\begin{array}{l}43 / 107 \\
(40.2 \%)\end{array}$ & $4 / 6(66.6 \%)$ & 0.491 & $\begin{array}{l}9 / 17 \\
(52.9 \%)\end{array}$ & $41 / 103(39.8 \%)$ & 0.309 \\
\hline LDH - Raised & $7 / 7(100 \%)$ & $\begin{array}{l}82 / 112 \\
(73.2 \%)\end{array}$ & $0 / 1(0 \%)$ & 0.057 & $7 / 7(100 \%)$ & $\begin{array}{l}77 / 107 \\
(71.9 \%)\end{array}$ & $5 / 6(83.3 \%)$ & 0.313 & $\begin{array}{l}13 / 17 \\
(76.4 \%)\end{array}$ & $\begin{array}{l}76 / 103 \\
(73.7 \%)\end{array}$ & 0.565 \\
\hline Stage - III, IV & $3 / 7(42.9 \%)$ & $\begin{array}{l}65 / 112 \\
(58.4 \%)\end{array}$ & $0 / 1(0 \%)$ & 0.334 & $6 / 7(85.7 \%)$ & $\begin{array}{l}58 / 107 \\
(54.2 \%)\end{array}$ & $4 / 6(66.7 \%)$ & 0.211 & $\begin{array}{l}11 / 17 \\
(64.7 \%)\end{array}$ & $\begin{array}{l}57 / 103 \\
(55.3 \%)\end{array}$ & 0.470 \\
\hline \multicolumn{12}{|c|}{ Treatment outcome - CR rate } \\
\hline RCHOP-like & $0 / 3(0.0 \%)$ & $41 / 60(68.3 \%)$ & $0 / 1(0 \%)$ & 0.014 & NA & $\begin{array}{l}40 / 60 \\
(66.6 \%)\end{array}$ & $1 / 4(25 \%)$ & 0.093 & $2 / 7(28.5 \%)$ & $39 / 57(68.4 \%)$ & 0.038 \\
\hline CHOP-like & $0 / 2(0.0 \%)$ & $9 / 32(28.1 \%)$ & NA & 0.615 & $0 / 3(0 \%)$ & $9 / 31(34.7 \%)$ & NA & 0.004 & $1 / 3(33.3 \%)$ & $8 / 31(25.8 \%)$ & 0.720 \\
\hline \multicolumn{12}{|c|}{ Treatment outcome - 2-year survival rate } \\
\hline RCHOP-like & $1 / 3(33 \%)$ & $46 / 60(77 \%)$ & $0 / 1(0 \%)$ & $<0.01$ & NA & $47 / 60(78 \%)$ & $0 / 4(0 \%)$ & $<0.01$ & $3 / 7(42 \%)$ & $44 / 57(77 \%)$ & 0.018 \\
\hline CHOP-like & $0 / 2(0 \%)$ & $16 / 32(50 \%)$ & NA & $<0.01$ & $0 / 3(0 \%)$ & $15 / 31(48 \%)$ & NA & $<0.01$ & $1 / 3(33 \%)$ & $14 / 31(45 \%)$ & 0.619 \\
\hline \multicolumn{12}{|c|}{ Treatment outcome - median OS (IQR) (month) } \\
\hline RCHOP-like & 13.6 (NA) & $29.6(19)$ & 1.5 & $<0.01$ & NA & $30.0(19)$ & $8.2(16)$ & $<0.01$ & $16.6(7)$ & $29.6(17)$ & 0.018 \\
\hline CHOP-like & $6.5(5)$ & $22.2(21)$ & NA & $<0.01$ & $7.0(11)$ & $22.6(21)$ & NA & $<0.01$ & $15.3(6)$ & $21.7(14)$ & 0.619 \\
\hline \multicolumn{12}{|c|}{ Correlation with protein expression } \\
\hline $\begin{array}{l}\text { Positive MYC } \\
\text { protein expression }\end{array}$ & $7 / 7(100 \%)$ & $70 / 112(62.5 \%)$ & $1 / 1(100 \%)$ & 0.066 & NA & NA & NA & NA & NA & NA & NA \\
\hline $\begin{array}{l}\text { Positive BCL2 } \\
\text { protein expression }\end{array}$ & NA & NA & NA & NA & $6 / 7(85.7 \%)$ & $\begin{array}{l}86 / 107 \\
(80.3 \%)\end{array}$ & $6 / 6(100 \%)$ & 0.841 & NA & NA & NA \\
\hline $\begin{array}{l}\text { Positive BCL6 } \\
\text { protein expression }\end{array}$ & NA & NA & NA & NA & NA & NA & NA & NA & $\begin{array}{l}11 / 17 \\
(64.7 \%)\end{array}$ & $\begin{array}{l}76 / 103 \\
(73.7 \%)\end{array}$ & 0.558 \\
\hline
\end{tabular}

CR: complete response; EBER: Epstein-Barr virus encoded ribonucleic acid; GCB: germinal center B-cell; IPI: International Prognostic Index; IQR: interquartile range; LDH: lactate dehydrogenase; NA: not applicable; OS: overall survival; SD: standard deviation

The only case with extra copies of $c-M y c$ gene was a 71 year-old male patient who had DLBCL on his lymph node. His tumor was categorized as non-GCB subtype, stage 11 disease, IPI score of 1 , and achieved partial remission after RCHOP-like therapy. This patient survived for only 1.5 month after diagnosis, and died due to sepsis.

Of the 120 cases analyzed, 7 cases were positive for BCL2 gene rearrangement $(5.8 \%)$ and 6 cases were found to have extra copies of BCL2 gene. The 
prevalence of $B C L 2$ gene rearrangement was higher among GCB subtype-DLBCL $(9.7 \%)$ compared to the non-GCB subtype-DLBCL $(4.5 \%)$. Of the 7 cases, 4 underwent SCT after receiving RCHOP-like chemotherapy regimens, and the remaining 3 patients were treated with CHOP-like chemotherapy; none of these three patients achieved complete remission $(P=0.004)$. Significant shorter median overall survival period was observed in CHOP-like treated-BCL2 gene rearrangement positive group compared to $\mathrm{CHOP}$ like treated-BCL2 gene rearrangement negative group (7.0 months \pm 3.5 versus 22.6 months $\pm 2.0, P<0.01$ ).

2-year survival rate for CHOP-like treated-BCL2 gene rearrangement positive group was $0 \%$; and $48 \%$ for CHOP-like treated-BCL2 gene rearrangement negative group. No significant correlation was observed between $B C L 2$ gene rearrangement and IPI score $(42.8 \%$ with high IPI scores of 3 to $5, P=0.491)$; and with disease stage $(85.7 \%$ with high disease stage 111 to $\mathrm{lV}, P=0.211$ ).

Of the 6 cases of extra copies of BCL2 gene, four patients were treated with RCHOP-like chemotherapy, one was treated with Methotrexate based chemotherapy, and the remaining one patient was not fit for treatment. Extra copies of BCL2 gene were associated with lower $\mathrm{CR}$ rate $(25 \%$ versus $66.6 \%$, $P=0.093)$. Overall, probability of survival at 24 months was $0 \%$ for extra copies of BCL2 gene group and $78 \%$ for those without extra copies of BCL2 gene. Median OS for RCHOP treated patients with extra copies of $B C L 2$ gene was significantly shorter than those without extra copies of $B C L 2$ gene (8.2 months \pm 4.9 versus $30.0 \pm 1.4, P<0.01)$. Extra copies of $B C L 2$ gene were often found in non-GCB subtype (6 of 6 cases or $100 \%, P=0.198$ ), had elevation of serum LDH (5 of 6 cases or $83.3 \%, P=0.313$ ) and expressed BCL2 protein ( 6 of 6 cases or $100 \%, P=0.841$ ).

BCL6 genetic abnormalities were detected in $14.1 \%$ (17 cases); $11.6 \%$ (14 of 120 ) of them had sole BCL6 gene rearrangement, $1.6 \%$ (two cases) had concurrent BCL2 and BCL6 gene rearrangements and 1 case $(0.8 \%)$ of concurrent $B C L 6$ gene rearrangement and extra copies of BCL2 gene. BCL6 gene rearrangement was more prevalent among female patients $(70.5 \%, P=0.033)$ and majority had extranodal disease involvement $(52.9 \%, P=0.029)$. Of the 17 patients with BCL6 gene rearrangement, seven patients were treated with RCHOP-like chemotherapy, three patients with CHOP chemotherapy, three patients with SCT, two patients with $\mathrm{EPOCH}$, one patient with Methotrexate regimen, and the remaining one patient with palliative therapy. In RCHOP-like treated group, CR rate was much higher in of BCL6 gene rearrangement negative patients compared to the BCL6 gene rearrangement positive patients $(68.4 \%$ versus $28.5 \%, P=0.038)$. RCHOP-like treated BCL6 gene rearrangement positive group had shorter median OS compared to the RCHOP-like treated BCL6 gene rearrangement negative group (16.6 months \pm 3.5 versus 29.6 months $\pm 1.5, P=0.018$ ) . 2-year survival rate for RCHOP-like treated-BCL6 gene rearrangement positive group was rather low compared to RCHOP-like treated-BCL6 gene rearrangement negative group ( $42 \%$ versus $77 \%$ ).

In this study, weak correlation was found between MYC protein expression and $c-M y c$ gene rearrangements $(P=0.066)$. No significant correlation was found between BCL2 protein expression and $B C L 2$ gene rearrangement $(P=0.841)$; and between BCL6 protein expression and BCL6 gene rearrangement $(P=0.558)$.

Comparing the prognosis values of these three gene rearrangements, we found no significant difference in the median OS between RCHOP-like treated-c-Myc gene rearrangement positive group and RCHOP treated-BCL6 gene rearrangement positive group (13.6 months \pm 4.6 for versus 16.6 months \pm 3.5 , $P=0.837$ ); with 2-year survival rate for $\mathrm{RCHOP}$ treated-cMyc rearrangement positive group versus RCHOP treated-BCL6 gene rearrangement positive group of $33 \%$ versus $42 \%$.

None of the CHOP-like treated patients with positive $c-M y c$ or $B C L 2$ gene rearrangements survived for 24 months while $33 \%$ of the patients with BCL6 gene rearrangement survived for more than 24 months. The differences in median OS for these three groups with positive $c-M y c, B C L 2$ and $B C L 6$ gene rearrangements were statistically insignificant $(6.5$ months \pm 2.5 for positive $c-M y c$ gene rearrangement group, 7.0 months \pm 3.5 for $B C L 2$ gene rearrangement positive group, and 15.3 months \pm 6.1 for $B C L 6$ gene rearrangement positive group, $P=0.191$ ) .

\section{Discussion}

The clinicopathological features of our study cohort were quite distinct compared to those reported in western countries. Median age of diagnosis for this study cohort was 54.1 years \pm 14.6 ; it was 70 years for the western DLBCL population [19]. Male gender has been found to be associated with poorer treatment outcome [20]. The male to female ratio for this study cohort (1.14:1) was similar to the Japanese's (1.18:1), but was lower than the Caucasian's (1.7:1) [21]. The diagnostic specimen sites for this study cohort (43.3\% of lymph nodes, $14.2 \%$ of Waldeyer's ring samples, $42.5 \%$ of extranodal tissue) were consistent with the western's with $60 \%$ of nodal disease and $40 \%$ of extranodal involvement [22].

Incidence rate of EBER positive cases was quite low $(6.7 \%)$ and majority of them had low IPI scores of 
1 to $2(87.5 \%)$, which was shown in Nicolae A et al. 2015's study [23]. EBER positivity showed no correlation with older age of diagnosis and sites of disease. These findings contradict previous publications which suggested EBER positivity is associated with old age [24] and was frequent in extranodal [25]. Despite low IPI scores, EBER-positive group demonstrated poorer treatment outcome compared to the EBER-negative group, indicating that EBER positivity is an independent risk factor of poor prognosis. RCHOP-like treatment did not improve treatment outcome of EBER positive patients, as evident in previous publications [25][26].

Clinicopathological characteristics of Malaysian DLBCL with positive CD5 protein expression diverge from the western population and Japanese who demonstrated older median age diagnosis (63 years), female preponderance, and predominant of extranodal involvement [27][28]. However, all studies demonstrated similar treatment failure pattern. In this study cohort, disease refractory rate was rather high (75\%) among patients with positive CD5 protein expression. Similarly, Thakral et al. 2017 and Miyazaki et al. 2011 reported higher disease relapse in the central nervous system of diffuse large B-cell lymphoma patients with positive CD5 protein expression [29][30], while Alinari L et al. 2016 reported $71 \%$ of disease relapse in positive CD5 protein expression-DLBCL patients treated with SCT [31]. The insignificant difference in median OS period between patients with and without positive CD5 protein expression could be due to small sample size in this study cohort.

The prevalence of GCB (25.8\%) and non-GCB (74.2\%) in our cohort is comparable to other Asian countries (GCB 29\%, non-GCB 71\%) [32] and another study in Malaysia study [33], but the westerners reported higher percentage of GCB subtype $(42 \%)$ [14]. In this study, no significant difference in treatment outcome was found between GCB and non-GCB subtypes $(P>0.05)$. Disease prognostication based on GCB/non-GCB sub-categorization in previous publications was contradictory. Some studies suggested that GCB subtype patients have superior treatment outcome than the non-GCB subtype [34][35][36], whereas a few studies showed no significant difference in $O S$ and disease free survival period between GCB subtype and non-GCB subtype [33][37]. Our results showed that there was no significant difference in $C R$ rate $(P=0.142)$ and median OS $(P=0.361)$ between GCB subtype and nonGCB subtype in RCHOP-like treated-DLBCL patients, which is in concordance with some published literatures [33][38][39][40]. Likewise for patients on CHOPlike treatment ( $C R$ rate $P=0.872$, median OS $P=0.895$ ).
Our results showed that DPL had poorer median OS for both RCHOP-like and CHOP-like groups. The insignificant $P$ value of $P=0.080$ and $P=0.089$ in our results were most probably due to small sample size. International prognostic index remains as a significant factor affecting OS of the DPL patients. Other study using dual immunohistochemistry technique with cutoff value of $0.12 \%$ for positive MYC/BCL2 proteins co-expression also showed consistent findings [41]. In this study, comparison of OS between DPL and DHL cannot be performed as both the DHL patients had been treated with SCT.

Besides that, TPL patients had significant poorer median OS compared to the non-TPL, and the finding is consistent with another study which showed that TPL is associated with inferior OS and worse progression free survival [42].

The prevalence of $c-M y c$ (5.8\%), BCL2 (5.8\%) and BCL6 (14.1\%) gene rearrangements in our study cohort were lower compared to the western countries, with $c-M y c$ of $7 \%$ [43], BCL2 of $18.3 \%$ [44] and BCL6 of $19.5 \%$ [45]. All three c-Myc, BCL2, BCL6 gene rearrangements and extra copies of $B C L 2$ gene were independent prognostic factors for inferior OS $(P<0.05)$ and low $\mathrm{CR}$ rates. In $\mathrm{RCHOP}$-like-treated group, disease relapse or refractory rates were higher among patients with $c-M y c$ gene rearrangement (100\%, $P=0.014)$; extra copies of BCL2 gene $(75 \%$, $P=0.093)$ and also BCL6 gene rearrangement $(71.5 \%$, $P=0.038)$. RCHOP-like and CHOP-like chemotherapy regimens did not improve treatment outcomes of patients with c-Myc, BCL2 and BCL6 gene rearrangements and extra copies of $B C L 2$ gene. It has been suggested that deregulated $c-M y c$ gene could activate $\gamma \mathrm{H} 2 \mathrm{AX}$ foci and sensitizes cellular DNA repair machinery and contribute to chemoresistance [46]. In addition, changes to $B C L 2$ gene copy number or $B C L 2$ gene structure have also been identified as the mechanisms contributing to treatment resistance [47].

The incidence of DHL is rather uncommon $(1.6 \%)$ in our Malaysian DLBCL study cohort. This is most likely due to younger DLBCL patients in Malaysia (median age of diagnosis of 54.1 years \pm 14.6) compared to the western countries (with median age of diagnosis of 70.6 years) [48].

\section{Conclusion}

EBER positivity, c-Myc, BCL2, BCL6 gene rearrangements or extra copies of these genes, IPI score, DPL and TPL are useful prognostication tools in DLBCL. No significant correlation were found between treatment outcomes and GCB/non-GCB sub-categorization; and expression of CD5 protein. Immunohistochemical staining of MYC, BCL2 and BCL6 proteins cannot be used as baseline markers to 
predict $c-M y c, B C L 2, B C L 6$ gene rearrangements.

\section{Abbreviations}

EBV: Epstein-Barr virus; DA-EPOCH-R: doseadjusted etoposide, cyclophosphamide, doxorubicin, vincristine, prednisone, and rituximab; EBER: Epstein Barr virus encoded RNA; RCHOP: rituximab, cyclophosphamide, doxorubicin, vincristine, and prednisone; IPI: international prognostic index score; BCL2: b-cell lymphoma-2; MYC: Myelocytomatosis; BCL6: b-cell lymphoma-6; CD10: cluster of differentiation 10; MUM1: multiple myeloma-1; CD5: cluster of differentiation-5; DPL: Double Protein Expression Lymphoma; TPL: Triple Protein Expression Lymphoma.

\section{Acknowledgements}

We would like to thank the Director General of Health Malaysia for permission to publish this paper. Special thanks to Mr. Erwin Ng Tze Hau and Mr. Kew Kok Pen for their valuable and timely english language editing services.

\section{Funding}

This work was supported by a research grant from the Ministry of Health Malaysia. The funders did not involve in study design, results collection, data analysis, and manuscript preparation.

\section{Authors' Contributions}

Project leader and study design: Chang KM. Wrote the paper and bioinformatics analysis: Ting CY. Co-wrote the manuscript: Kuan JW. Performed immunohistochemistry testing and FISH testing: Ting CY. Slides review and performed Histopathology analysis: Samsudin AT, Wong JOL, Yusuf Y, Raja Gopal N, Puri R, Bahari SK. Data collection: Wong LLL, Chew LP, Lee SK, Ong TC, Goh AS and Teoh CS, Mohd Nurjaya.

\section{Availability of data and materials}

All test methods and data analysed in this study are presented in this article. Results and laboratory findings are tabulated in the supplementary file 1, supplementary file 2 and supplementary file 3 .

\section{Competing Interests}

The authors have declared that no competing interest exists.

\section{References}

1. Joy KA, Ndindjock R, Coyle KB, et al. The Burden Of Illness and Prevalence In Diffuse Large B Cell (DLBCL) and Follicular (FL) Lymphomas. Blood. 2013; 122(21): 5619.

2. Peh S, Shaminie J, Jayasurya $P$, et al. Spectrum of malignant lymphoma in Queen Elizabeth Hospital, Sabah. The Medical journal of Malaysia. 2003; 58(4): 546-555.
3. International Non-Hodgkin's Lymphoma Prognostic Factors Project. A predictive model for aggressive non-Hodgkin's lymphoma. New England Journal of Medicine. 1993; 329(14): 987-994.

4. Kim YR, Kim S, Cheong J, et al. Upfront Autologous Stem Cell Transplantation Overcome the poor Prognosis of Non-Germinal Center Subtype of diffuse Large B-Cell Lymphoma in Patients with Advanced Stage and Elevated Serum Lactate Dehydrogenase. Blood. 2014; 124(21): 3998.

5. Wilson WH, Dunleavy K, Pittaluga S, et al. Phase II study of dose-adjusted EPOCH-rituximab in untreated diffuse large B-cell lymphoma with analysis of germinal center and post-germinal center biomarkers. Journal of clinical oncology. 2008; 26(16): 2717-2724.

6. Wilson WH, Young RM, Schmitz R, et al. Targeting B cell receptor signaling with ibrutinib in diffuse large B cell lymphoma. Nature Medicine. 2015; 21(8): 922-928.

7. Dunleavy K, Pittaluga S, Czuczman MS, et al. Differential efficacy of bortezomib plus chemotherapy within molecular subtypes of diffuse large B-cell lymphoma. Blood. 2009; 113(24): 6069-6076.

8. Ott G, Ziepert M, Klapper W, et al. Immunoblastic morphology but not the immunohistochemical GCB/nonGCB classifier predicts outcome in diffuse large B-cell lymphoma in the RICOVER-60 trial of the DSHNHL. Blood. 2010; 116(23): 4916-4925.

9. Tsuyama N, Ennishi D, Yokoyama M, et al. Clinical and prognostic significance of aberrant T-cell marker expression in 225 cases of de novo diffuse large B-cell lymphoma and 276 cases of other B-cell lymphomas. Oncotarget. 2017; 8(20): 33487.

10. Schuetz JM, Johnson NA, Morin RD, et al. BCL2 mutations in diffuse large B-cell lymphoma. Leukemia. 2012; 26(6): 1383.

11. Said JW. Aggressive B-cell lymphomas: how many categories do we need? Modern Pathology. 2012; 26(S1): S42.

12. Swerdlow SH, Campo E, Pileri SA, et al. The 2016 revision of the World Health Organization classification of lymphoid neoplasms. Blood. 2016; 127(20): 2375-2390

13. Cheson BD, Fisher RI, Barrington SF, et al. Recommendations for initial evaluation, staging, and response assessment of Hodgkin and non-Hodgkin lymphoma: the Lugano classification. Journal of Clinical Oncology. 2014; 32(27): 3059-3067.

14. Hans CP, Weisenburger DD, Greiner TC, et al. Confirmation of the molecular classification of diffuse large B-cell lymphoma by immunohistochemistry using a tissue microarray. Blood. 2004; 103(1): 275-282.

15. Johnson NA, Slack GW, Savage KJ, et al. Concurrent expression of MYC and BCL2 in diffuse large B-cell lymphoma treated with rituximab plus cyclophosphamide, doxorubicin, vincristine, and prednisone. Journal of Clinical Oncology. 2012; 30(28): 3452.

16. Lu TX, Liang JH, Miao Y, et al. Epstein-Barr virus positive diffuse large B-cell lymphoma predict poor outcome, regardless of the age. Scientific Reports. 2015; 5: 12168.

17. Kim H, Yoo SB, Choe JY, et al. Detection of ALK gene rearrangement in non-small cell lung cancer: a comparison of fluorescence in situ hybridization and chromogenic in situ hybridization with correlation of ALK protein expression. Journal of Thoracic Oncology. 2011; 6(8):1359-1366.

18. Bellas C, García D, Vicente $Y$, et al. Immunohistochemical and molecular characteristics with prognostic significance in diffuse large B-cell lymphoma. PloS One. 2014; 9(6): e98169.

19. Smith A, Howell D, Patmore R, et al. Incidence of haematological malignancy by sub-type: a report from the Haematological Malignancy Research Network. British Journal of Cancer. 2011; 105(11): 1684.

20. Yamauchi A, Fujita S, Ikeda J, et al. Diffuse large B-cell lymphoma in the young in Japan: A study by the Osaka Lymphoma Study Group. American Journal of Hematology. 2007; 82(10): 893-897.

21. Burkhardt B, Zimmermann M, Oschlies I, et al. The impact of age and gender on biology, clinical features and treatment outcome of non-Hodgkin lymphoma in childhood and adolescence. British Journal of Haematology. 2005; 131(1): 39-49.

22. Møller MB, Pedersen NT, Christensen BE. Diffuse large B-cell lymphoma: clinical implications of extranodal versus nodal presentation-a population-based study of 1575 cases. British Journal of Haematology. 2004; 124(2): 151-159.

23. Nicolae A, Pittaluga S, Abdullah S, et al. EBV-positive large B-cell lymphomas in young patients: a nodal lymphoma with evidence for a tolerogenic immune environment. Blood. 2015; 126(7): 863-872.

24. Oyama T, Yamamoto K, Asano N, et al. Age-related EBV-associated B-cell lymphoproliferative disorders constitute a distinct clinicopathologic group: a study of 96 patients. Clinical Cancer Research. 2007; 13(17): 5124-5132.

25. Sato A, Nakamura N, Kojima M, et al. Clinical outcome of Epstein-Barr virus-positive diffuse large B-cell lymphoma of the elderly in the rituximab era. Cancer Science. 2014; 105(9): 1170-1175.

26. Song CG, Huang JJ, Li YJ, et al. Epstein-barr virus-positive diffuse large B-cell lymphoma in the elderly: A matched case-control analysis. PloS One. 2015; 10(7): e0133973.

27. Jain P, Fayad LE, Rosenwald A, et al. Recent advances in de novo CD5+ diffuse large B cell lymphoma. American Journal of Hematology. 2013; 88(9): 798-802.

28. Yamaguchi M, Nakamura N, Suzuki R, et al. De novo CD5+ diffuse large B-cell lymphoma: results of a detailed clinicopathological review in 120 patients. Haematologica. 2008; 93(8): 1195-1202. 
29. Thakral B, Medeiros LJ, Desai P, et al. Prognostic impact of CD5 expression in diffuse large B-cell lymphoma in patients treated with rituximab-EPOCH. European Journal of Haematology. 2017; 98(4): 415-421.

30. Miyazaki K, Yamaguchi M, Suzuki R, et al. CD5-positive diffuse large B-cell lymphoma: a retrospective study in 337 patients treated by chemotherapy with or without rituximab. Annals of Oncology. 2011; 22(7): 1601-1607.

31. Alinari L, Gru A, Quinion C, et al. De novo CD5+ diffuse large B-cell lymphoma: Adverse outcomes with and without stem cell transplantation in a large, multicenter, rituximab treated cohort. American Journal of Hematology. 2016; 91(4), 395-399.

32. Shiozawa E, Yamochi-Onizuka T, Takimoto M, et al. The GCB subtype of diffuse large B-cell lymphoma is less frequent in Asian countries. Leukemia Research. 2007; 31(11): 1579-1583.

33. Phang KC, Akhter A, Tizen NM, et al. Comparison of protein-based cell-of-origin classification to the Lymph2Cx RNA assay in a cohort of diffuse large B-cell lymphomas in Malaysia. Journal of clinical pathology. 2017; Aug

34. Chavez J, Walsh M, Hernandez-llizaliturri FJ, et al. Classification of Newly Diagnosed Diffuse Large B-Cell Lymphoma (DLBCL) According to the Han's Criteria Defines Two Groups of Patients with Different Clinical Outcomes Following Systemic Rituximab-Multi Agent Anthracycline-Based Therapy. Blood. 2009; 114(22): 623.

35. Lu TX, Miao Y, Wu JZ, et al. The distinct clinical features and prognosis of the CD10+ MUM1+ and CD10- Bcl6- MUM1- diffuse large B-cell lymphoma. Scientific Reports. 2016; 6: 20465.

36. Meyer PN, Fu K, Greiner TC, et al. Immunohistochemical methods for predicting cell of origin and survival in patients with diffuse large B-cell lymphoma treated with rituximab. Journal of Clinical Oncology. 2011; 29(2): 200.

37. Dwivedi A, Mehta A, Solanki P, et al. Evaluation of immunohistochemical subtypes in diffuse large B-cell lymphoma and its impact on survival. Indian Journal of Pathology and Microbiology. 2015; 58(4): 453.

38. Benesova K, Forsterova K, Votavova $\mathrm{H}$, et al. The Hans algorithm failed to predict outcome in patients with diffuse large B-cell lymphoma treated with rituximab. Neoplasma. 2013; 60(1): 68-73.

39. Hong J, Park S, Park J, et al. Evaluation of prognostic values of clinical and histopathologic characteristics in diffuse large B-cell lymphoma treated with rituximab, cyclophosphamide, doxorubicin, vincristine, and prednisolone therapy. Leukemia and Lymphoma. 2011; 52(10): 1904-1912.

40. Castillo JJ, Beltran BE, Song MK, et al. The Hans algorithm is not prognostic in patients with diffuse large B-cell lymphoma treated with R-CHOP. Leukemia Research. 2012; 36(4): 413-417.

41. Roh J, Yoon DH, Huh J, et al. Concurrent Overexpression of MYC and BCL2 by Dual Immunohistochemistry Is Associated with Poor Prognosis in Diffuse Large B-cell Lymphoma. American Journal of Clinical Pathology. 2016; 146(suppl_1).

42. Yan LX, Liu YH, Luo DL, et al. MYC expression in concert with BCL2 and BCL6 expression predicts outcome in Chinese patients with diffuse large B-cell lymphoma, not otherwise specified. PLoS One. 2014; 9(8): e104068.

43. Valera A, López-Guillermo A, Cardesa-Salzmann T, et al. MYC protein expression and genetic alterations have prognostic impact in patients with diffuse large B-cell lymphoma treated with immunochemotherapy. Haematologica. 2013; 98(10): 1554-1562.

44. Visco C, Tzankov A, Xu-Monette ZY, et al. Patients with diffuse large B-cell lymphoma of germinal center origin with BCL2 translocations have poor outcome, irrespective of MYC status: a report from an International DLBCL rituximab-CHOP Consortium Program Study. Haematologica. 2013; 98(2): $255-263$

45. Shustik J, Han G, Farinha P, et al. Correlations between BCL6 rearrangement and outcome in patients with diffuse large B-cell lymphoma treated with CHOP or R-CHOP. Haematologica. 2010; 95(1):96-101.

46. Kumari A, Folk WP, Sakamuro D. The Dual Roles of MYC in Genomic Instability and Cancer Chemoresistance. Genes. 2017; 8(6):158.

47. Yasui K, Mihara S, Zhao C, et al. Alteration in copy numbers of genes as a mechanism for acquired drug resistance. Cancer research. 2004; 64(4): 1403-10.

48. Smith A, Howell D, Patmore R, et al. Incidence of haematological malignancy by sub-type: a report from the Haematological Malignancy Research Network. British journal of cancer. 2011; 105(11): 1684 